\title{
PEDAGOGÍA TEATRAL PARA EL APRENDIZAJE DEL ALEMÁN TOI, TOI, TOI THEATER\&DEUTSCH presenta GRENZEN (Experiencia práctica)
}

\author{
Leticia García Brea \\ Centro de Idiomas \\ Universidad de León
}

http://dx.doi.org/10.12795/mAG Azin.2016.i24.03

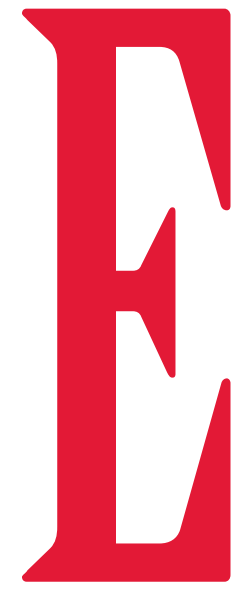

1 taller de teatro y alemán "Toi, toi, toi, Theater\&Deutsch" se creó en octubre de 2012 con el objetivo de experimentar con la pedagogía dramática en el proceso de aprendizaje del alemán. La tesis de inicio es que las herramientas pedagógicas del arte dramático pueden ser de gran utilidad en el proceso de adquisición de una segunda lengua, en este caso, el alemán. Se parte de la similitud entre el proceso de formación de un actor y el proceso de adquisición de una lengua por parte de un estudiante. Al componente de expresión artística se le une el componente lúdico, el aprendizaje a través del juego. Esta es la idea base sobre la que echa a andar Toi, toi, toi.

\section{Toi, toi, toi, un taller de teatro para aprender alemán y viceversa}

Tras cinco años de existencia, el taller se ha convertido en un grupo estable de teatro que crea y representa sus obras fundamentalmente en alemán y que vuelca su atención en la experiencia escénica y el proceso de creación como partes integrantes e imprescindibles del trabajo.

En este artículo se pretende relatar la experiencia práctica del proceso creativo detrás de Grenzen, el montaje teatral del curso 2015/16: cómo surge la propuesta, cómo se propone el trabajo, cómo se lleva a cabo y con qué resultados. En la última parte se dará voz a los actores implicados, léase, los alumnos del taller y nuestro técnico. Nos contarán de primera mano lo que el trabajo en el proyecto de Grenzen ha significado para ellos y en que medida ha contribuido a su aprendizaje de la lengua alemana.

La propuesta de trabajo llega a Toi, toi, toi después de un largo recorrido. Grenzen no hubiese sido un proyecto de este grupo si no se hubiesen dado alguno de los encuentros que a continuación van a relatarse. La idea original es el fruto de un fuerte deseo de trabajo conjunto de un grupo de profesoras de alemán provenientes de diferentes rincones del país y con historias distintas, pero con un objetivo en común: trabajar con el teatro y el alemán.

\section{Netzwerk: el inicio}

Después de conocernos a través de varios proyectos teatrales y formativos, el grupo de profesoras que coincidimos en las dos primeras ediciones de la Escuela de Teatro de verano de Tordera (Barcelona), organizado por el Goethe Institut de Madrid, decidimos que era el momento de pasar a la acción. Las iniciativas planteadas desde el Goethe habían sido el comienzo de algo, y no podíamos dejar esa energía sin mover. Así que nos pusimos manos a la obra y tras la segunda escuela de verano en Tordera, creamos una red o "Netzwerk" de profesoras y presentamos el trabajo teatral realizado con los alumnos en el Deutschlehrertag de noviembre de 2015 en Madrid. Bárbara González, Cristina Ortega y Doris Renggli presentaron sus proyectos teatrales en los festivales organizados por el Goethe: “Transit” y "Trans- Eur(h)ope” entre otros y a su vez, Leticia García y Arthur Häring impartimos un taller de actividades teatrales para la clase de DaF.

Tras el Deutschlehrertag, le propusimos al Goethe Institut la organización de un encuentro entre nuestros 
alumnos de los talleres de teatro en sus instalaciones. Después de varias conversaciones con Herr Karsten Wiemann (Asesor pedagógico) e Isabel Gavidia (Secretariado Servicio Pedagógico y Dirección Académica), nació el Encuentro de Teatro joven del Goethe Institut: Jugendtheaterfestival el 16 de abril de 2016.

\section{Grenzen: el impulso creador}

Una vez propuesta la idea sobre la cual trabajar Grenzen, comenzaron los ensayos. Toi, toi, toi se reúne normalmente una vez a la semana en el salón de actos del Centro de Idiomas de la Universidad de León, su cuartel general. Para este proyecto nos reunimos durante los meses de enero a abril los viernes por la tarde y sábados por la mañana. El montaje se puso en pie en un total de tres meses, ensayando una media de tres horas semanales.

La idea original, el material gráfico, los textos y la puesta en escena son creación del grupo, a excepción de la tercera escena, que es una traducción libre y adaptación del poema "Home" de Warsan Shire. El montaje final dura en total 35 minutos, está dividido en tres escenas o actos introducidos todos ellos por unos audios en alemán y español. A continuación se relatará el proceso de creación.

\section{Primeras sesiones: concepto y estructura del montaje}

En la primera sesión se estableció con los alumnos el tipo de trabajo que se iba a realizar. El concepto a partir del cual había que crear el montaje era Grenzen. La obra se iba a estructurar en tres o cuatro actos o escenas independientes y todo iba a comenzar con el "secuestro de un teatro". Esta última idea se basaba en el deseo expreso de la directora de comenzar de una forma potente el montaje.

Una vez establecido el concepto y la estructura, comenzó el intercambio y la lluvia de ideas. En el taller de teatro Toi, toi, toi trabajamos habitualmente en alemán. Utilizamos la lengua con el fin de comunicarnos y llevar a cabo los juegos y actividades del taller. Sin embargo, cuando nos sumergimos en el montaje de una obra, nuestra lengua común y materna suele ganarle a la lengua de estudio, por razones obvias de comunicación y presteza. En ocasiones las ideas que se exponen en la creación de un montaje son complejas y necesitan ser expresadas en castellano. En esta ocasión, la exposición de las ideas comenzó con el trabajo de mesa en alemán, y poco a poco fue derivando a discusiones en español.

Comenzamos por investigar el significado de la palabra Grenzen en alemán, sus implicaciones y el alcance de su significado. Grenzen significa "límite, frontera", tanto en el sentido geográfico y político como en el sentido de barrera entre dos objetos, personas o comportamientos. Los alumnos escribieron en papeles todo lo que se les ocurría en relación al concepto Grenzen, discutimos las diferentes ideas y a partir de ahí se fueron perfilando los cuatro campos de acción, que terminarían siendo tres:

La primera escena, que comenzaría con el asalto al teatro, tendría que ver con los límites geográficos y la movilidad de personas, referida al conflicto actual de refugiados. La historia que queríamos contar tenía que exponer todas las partes implicadas en un conflicto bélico.

En la segunda escena decidimos hablar de los limites de la comunicación. A pesar de tener un idioma y la propia sangre en común, los dos protagonistas de esta escena, un padre y un hijo, se verán limitados por el lenguaje y su propia capacidad de expresión a la hora de entenderse en un conflicto. Queríamos mostrar los pensamientos y emociones que intervienen en el proceso de comunicación entre ambos personajes y se nos ocurrió personificar las emociones.

El planteamiento de la tercera escena tenía que ver con los límites de la moral y la ética en el desarrollo y aplicación de la ciencia y la tecnología en el mundo moderno. Por falta de tiempo no pudimos desarrollar esta escena, por lo que la idea no llegó a desarrollarse más.

El epílogo, que se convirtío en la tercera escena, sería una versión, adaptación y traducción a diferentes idiomas del poema "Home" de la escritora, poeta, editora y profesora somalí afincada en Londres Warsan Shire.

La idea de comenzar el montaje con el asalto y secuestro del público está basada en el asalto que se produjo en el teatro Dubrovka de Moscú en octubre de 2002 a manos de rebeldes chechenos. La Fura del Baus trabajó con este tema en su "Boris Godunov" ya en 2008. El poema de Warsan Shire llegó a mis manos a través de las redes sociales y del movimiento de apoyo a los refugiados surgido a finales de verano de 2015. Tanto el inicio como el final de la obra estaban propuestos desde la dirección. 


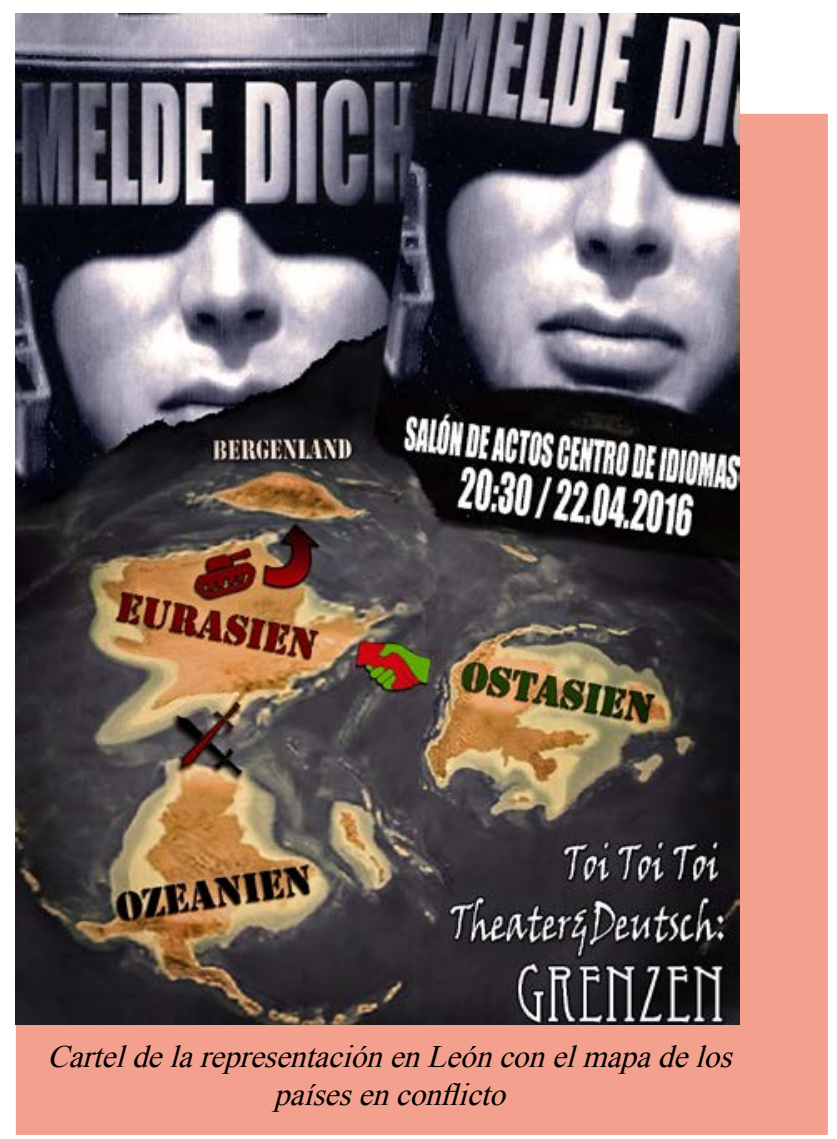

Teniendo en cuenta los temas elegidos, se fue perfilando un tono bélico bastante pronunciado. Por ello, durante los diferentes intercambios de ideas en la primera fase del montaje se discutió mucho sobre cómo plantear la obra sin caer en maniqueísmos. Todos estuvimos de acuerdo en que la obra debía exponer la realidad desde diferentes perspectivas, no sólo desde una. Llevaríamos a los personajes a situaciones límite, pero dejaríamos un final abierto. Nos pareció conveniente mantener este tono en la obra y reproducir al final de cada escena un audio bilingüe en el que se plantean cuestiones abiertas que inviten a la reflexión.

Escena 1: ¿El fin justifica los medios? ¿Dónde están los límites para conseguir un objetivo? ¿Se puede justificar realmente una muerte en nombre de la justicia? ¿En qué momento se traspasa la frontera de estar oprimido a ser opresor? ¿Cómo puede defenderse alguien en una situación de violencia?

Escena 2: ¿Qué nos impide expresar nuestras emociones y pensamientos? Expresar nuestros sentimientos, ¿nos hace más débiles o más fuertes? ¿Por qué existen barreras de comunicación entre los seres humanos? ¿De dónde proceden esas barreras? ¿Quién o qué nos las impone? ¿El idioma nos permite o nos limita la comunicación?
Con todo esto en mente, se nos ocurrió que la mejor forma de hablar de un conflicto era el de inventarse uno. Trabajar desde la distancia es más fácil a la hora de tratar con temas morales espinosos, y el teatro nos da una oportunidad de oro en este sentido. Creamos, pues, una realidad ficticia de la que partir con los ingredientes básicos de cualquier conflicto bélico de gran escala: intereses económicos, materias primas, invasión de países, destrucción de pueblos y de su soberanía, refugiados, dolor y más dolor. Para ello nos basamos en la realidad distópica de George Orwell en 1984, y así nació Bergenland, nuestro país ficticio inmerso en el conflicto de escala mundial entre Ostasien, Eurasien y Ozeanien.

Aunque aún nos quedaba por delante la tarea de crear la historia, los personajes, de presentar el conflicto de una manera plausible y de crear los textos, tener claro el planteamiento y estar todos de acuerdo marcó un comienzo muy fructífero. Como todos formábamos parte del concepto, lo habíamos discutido y estábamos convencidos de ello, el compromiso con la obra fue completo y absoluto desde el principio y a todos los niveles. A continuación, veremos el desarrollo del trabajo más teatral.

\section{Creación de personajes y trabajo corporal}

Las primeras sesiones de trabajo teatral se dedicaron al teatro físico y a la creación de personajes. Comenzamos con un calentamiento rutinario, algunos juegos para concentrarse, soltar el cuerpo y la voz y entrar en estado lúdico y teatral. A continuación, realizamos un trabajo de cuerpo de diversa índole: nos desplazamos por el espacio a diferentes ritmos, con diferentes emociones, formas de caminar o de interactuar distintas y exploramos la capacidad del movimiento y del gesto. Una de las clases la dedicamos enteramente al trabajo con colores.

\section{Trabajo con colores}

En este tipo de trabajo se proponen distintos colores asociados a distintas emociones y rasgos de carácter. Los alumnos se dejan llevar por la propuesta arropados por la música que trata de acompañar el trabajo y exploran su capacidad de acción y reacción desde una perspectiva nueva. Se propone, por ejemplo, el morado como un color retrospectivo, de ritmo calmado y de carácter apesadumbrado. A partir de estas indicaciones los alumnos investigan, con el color siempre presente, los movimientos 
y las sensaciones que van surgiendo. Otro ejemplo muy distinto sería el rojo, el color de la pasión, del nervio, de la rabia. Es el color que surge justo antes de una explosión, sus movimientos son verticales, hacia arriba, enérgicos y rápidos. Con esta nueva propuesta y una música que acompañe al color, los alumnos investigan por el espacio.

Este trabajo se realizó durante una sesión de dos horas y tuvo un gran impacto en los alumnos. Con este tipo de recurso, los alumnos adquieren herramientas expresivas y pueden recurrir a ellas a la hora de, por ejemplo, construir la calidad de movimiento de su personaje.

\subsection{Primera escena: asalto y secuestro del teatro}

Una vez teníamos claro el desarrollo de la primera escena, el asalto y secuestro del teatro, era necesario que la historia contase con unos protagonistas que moviesen la acción. Ya teníamos la realidad distópica en la que sucedían los hechos, y un relato bastante completo de cómo interactuaban las diferentes fuerzas y de la raíz del conflicto.

Para la creación de los personajes utilizamos el clásico de "la silla caliente". Un actor/ actriz se sienta frente al grupo, y va contestando tranquilamente a las preguntas que el grupo le vaya planteando. El actor o actriz responde a estas preguntas desde la perspectiva del personaje que quiere crear, y poco a poco, con ayuda de sus compañeros, va creando el relato de su vida. Las preguntas se realizan de menor a mayor complejidad y todas en alemán. Comienzan con: Wie heißt du? Woher kommst du? Wie alt bist du? Wo wohnst du? (cómo te llamas, de dónde vienes, cuántos años tienes, dónde vives) etc. Y se terminan planteando cuestiones más complejas y personalizadas, como: “¿qué le pasó a tu madre? ¿cómo te sientes al respecto? ¿qué necesitas hacer?" Estas preguntas les ayudan a meterse en el contexto y a crear una realidad para su personaje. Los datos de cada personaje se van apuntando y al final se pide al actor/actriz que haga un resumen de lo relatado.

Este trabajo se realizó también durante una sesión de dos horas. El compromiso escénico de cada uno de los participantes alcanzó en este momento su punto más álgido. A partir de este instante, cada uno creía en su personaje, le había dotado de una historia real, en todos los casos y sin excepción con una carga de dramatismo muy alta, propia de una situación bélica. El trabajo físico que vino después fue laborioso, pero llegó a buen término porque al tener unos personajes tan perfilados, fue muy fácil encontrar la calidad y energía del movimiento de cada uno de ellos.

\subsection{Segunda escena: papá, me voy a la guerra}

En la segunda escena continuamos dentro de la realidad distópica que hemos creado. Si la primera escena era una escena coral, con muchos personajes interactuando y teniendo un impacto similar sobre el desarrollo de la historia, en la segunda hay dos personajes principales, y el resto están supeditados a ellos, ya que son la personificación de sus emociones.

Los dos personajes principales son un padre y su hijo: el padre es un reconocido articulista antibélico; el hijo, decide unirse voluntariamente al ejército y luchar por una causa que cree justa. La escena tiene lugar cuando el hijo le comunica la noticia del alistamiento a su padre. El conflicto está servido. Y el teatro es conflicto.

Para crear los personajes principales utilizamos una simplificación del modelo de análisis actancial de Greimas. Aquí una breve explicación:

La propuesta de Greimas se centra en la descripción y clasificación de personajes no según lo que son, sino según lo que hacen en la medida en que participen en tres grandes ejes semánticos (la comunicación, el deseo y la prueba) (Barthes, 1974:30). Desde este punto de vista, la primera distinción que efectúa Greimas, a partir del cual se constituirán los demás actantes de forma paradigmática, será la del Sujeto y el Objeto, los cuales trazan la trayectoria de la acción y de la búsqueda del héroe o del protagonista (plagada de obstáculos que el sujeto debe vencer para progresar). Ambos se articulan en torno al eje del deseo: si el Sujeto es aquel que se mueve hacia el Objeto para conquistarlo, el Objeto es, por tanto, aquello hacia lo que hay que moverse.

En torno al eje Sujeto-Objeto se construyen otros ejes auxiliares con actantes contrapuestos: el Destinador (punto de origen del Objeto) y el Destinatario (quien recibe el Objeto con sus beneficios), que controlan los valores y se articulan en torno al eje del poder. Si el Destinador responde a la cuestión de qué mueve al Sujeto para que desee al Objeto, el Destinatario lo haría a la pregunta acerca 
del beneficiario de la obtención del Objeto.

En último lugar, el Ayudante y el Oponente producen las circunstancias, las ayudas y los obstáculos que el Sujeto encontrará en su búsqueda del Objeto. (Pérez Rufí, J.P.)

Ahora bien, en lugar de realizar el análisis sobre un texto ya existente para ayudarnos a construir cada personaje, tratamos de construir los personajes y el texto basándonos en el tipo de relaciones que se pueden crear a partir de este modelo. Simplificamos la cuestión preguntando a nuestros personajes ¿qué es lo que desean conseguir en la escena? ¿Cuál es su objeto u objetivo hacia el que se mueven? ¿Qué cosas, actitudes o hechos les van a ayudar a lograrlo (ayudante/oponente)? Las respuestas no se hicieron esperar, y las acordamos sólo después de un largo debate en otra sesión de dos horas.

El personaje del hijo desea lograr la aprobación del padre, quiere partir al frente con su bendición. El padre, al enterarse de la noticia, tiene como objetivo en la escena tratar de convencer a su hijo de que no se vaya. El resto de personajes se van a crear en función de estos dos. Cada uno va a tener tres emociones principales personificadas que le guíen en el proceso: la alegría (amarillo), el orgullo (gris) y el binomio miedo (azul)-ira (rojo). Cada una de las emociones se representa con un color.

Siguiendo con el esquema actancial, los ayudantes y oponentes de cada personaje serán sus propias emociones. La alegría sería la encargada de construir un puente comunicativo entre ambos donde puedan entenderse y llegar a un acuerdo (ayudante). El orgullo será la emoción que les impela a imponerse al deseo del otro (oponente). Este trabajo estructurado de los actantes en la escena nos ayudó a conseguir una historia completa con un nudo, desarrollo, clímax y desenlace coherentes y potentes.

\subsection{Tercera escena: acción poética}

Como ya se ha mencionado, tanto el impulso inicial del asalto al teatro como la última escena basada en el poema de Warsan Shire venían propuestas desde la dirección, pero ello no fue impedimento para que los alumnos se comprometieran con ambas escenas con igual pasión. En este caso leímos el poema juntos, cada uno seleccionó los versos que más le emocionaban y trabajamos con algunos de los fragmentos seleccionados por los alumnos.
El poema "Home" se había hecho viral en las redes sociales a causa de dos fenómenos. Fue durante finales del 2015 y principios de 2016 quizás cuando la sensibilización con el tema de los refugiados que tratan de llegar a Europa desde los diferentes países en conflicto (Siria el más golpeado) estaba en su punto más álgido. El actor Benedict Cumberbatch eligió unos versos de este poema y los hizo virales al recitarlos en varios vídeos en apoyo a los refugiados y sobre todo, al finalizar una serie de representaciones de mucho éxito de la obra de Shakespeare, Hamlet, en los teatros de Londres.

"No one leaves home unless

home is the mouth of a shark

You only run for the border

when you see the whole city

running as well. (...)

No one puts their children in a boat unless the water is safer than the land."

Warsan Shire

fragmentos de "Home"

Como el poema original estaba escrito en inglés, nuestra obra era en alemán, pero nuestro público mayoritariamente español, decidimos hacer de esta escena una escena plurilingüe. Con ayuda de algunas compañeras del Centro de Idiomas tradujimos los fragmentos seleccionados al alemán, español, inglés, francés, portugués e italiano, y a partir de ahí construimos de nuevo una escena coral, con personajes neutros. La fuerza del poema se vio claramente amplificada gracias, de nuevo, al compromiso de los alumnos con el mensaje. En esta última escena sí queríamos transmitir un mensaje alto y claro. "Nadie deja su hogar, al menos que su hogar sea la boca de un tiburón".

\section{Creación de texto}

Como acabamos de ver, la tercera escena ya contaba con un texto potente que marcó el ritmo y el trabajo. En el caso de las dos primeras, el texto tuvo que crearse desde cero, para lo cual utilizamos diferentes estrategias de creación.

\subsection{Texto bilingüe en la primera escena}

En el caso de los diálogos de la primera escena, fueron surgiendo durante el montaje de la misma a raíz de improvisaciones escénicas. Desde el primer momento, no 
obstante, se nos planteaba una dificultad... Como ya se ha mencionado, la obra se plantea en alemán, pero nuestro público es mayoritariamente español, y no siempre domina el idioma como para seguir la obra en sus momentos más complejos. Algunos incluso desconocen enteramente el idioma.

Decidimos trabajar para que el público pudiese seguir por completo la obra, y llegamos a una solución que nos agradó a todos. El grupo de rebeldes que asalta el teatro proviene en nuestro relato de un país distinto, por lo cual tenía mucho sentido que éstos hablasen en un idioma diferente al idioma general del público. Los rebeldes se comunicaban entre ellos en alemán, pero para conectar con el público repetían sus parlamentos en español, o incluso uno de los personajes (la jefa del comando que asalta el teatro) se hace traducir sus palabras cuando éstas van dirigidas al público, que no eran otros que los secuestrados. Esta solución lingüística nos permitió avanzar aún más en la trama de la escena, conseguir conectar con el público a un nivel emocional más alto y convirtió los diálogos y la lengua de Goethe en otro elemento escénico.

\subsection{Segunda escena: improvisación como elemento creador}

Para elaborar los diálogos de la segunda escena utilizamos algunos juegos clásicos de improvisación. Por ejemplo, para el texto de la segunda escena funcionó muy bien el juego de improvisación "Ich muss dir was sagen" (Tengo algo que decirte).

\section{"Ich muss dir was sagen" (Tengo algo que decirte)}

Dos actores en escena. El primero comienza con la frase "tengo algo que decirte" a lo que el otro debe responder "ya lo sé, y a partir de ahí desarrollan una escena breve. Por ejemplo:

A: Ich muss dir was sagen (Tengo algo que decirte)

B. Ich weiss, du bist schwanger (Ya los sé, estás embarazada)

A. Ja, genau, und ich weiß nicht, was meine Eltern denken werden...! (Sí, y no sé lo que van a pensar mis padres!)

B. ...

Para que la escena se desarrolle con éxito, y esto es una regla de oro en la improvisación, los actores tienen que aceptar las propuestas de sus compañeros y jugar con ellas. Este juego nos sirvió para producir los diálogos entre el padre y el hijo en la segunda escena. Después de trabajar un rato y desarrollar un montón de escenas hilarantes, les fui proponiendo que fuesen pasando unos y otros por los papeles del padre y del hijo. De las escenas improvisadas fui tomando notas que luego se convirtieron en partes del diálogo entre ambos. Por supuesto, el desarrollo de la escena, fue enteramente en alemán. De la espontaneidad de sus propuestas y la capacidad expresiva de su alemán nacieron los diálogos de toda la escena. Se puede decir que el texto les venía como un guante, puesto que estaba hecho a medida.

\section{Reflexiones}

A lo largo del artículo hemos visto las propuestas y soluciones creativas dadas en cada momento en cada fase del proceso. Muchas otras han quedado fuera por falta de espacio, tiempo y, quizás, pertinencia, pero de las aquí relatadas me gustaría destacar algunos aspectos fundamentales: la imbricación del trabajo teatral y el trabajo lingüístico y el compromiso escénico de los alumnos.

Durante el proceso creativo se ha atendido al trabajo escénico y de creación de personajes tanto desde el punto de vista teatral como desde el punto de vista lingüístico. Por un lado, se ha utilizado el juego, la improvisación y el trabajo físico con los colores (entre otros) para desarrollar el trabajo de personajes y de texto. Por el otro, se ha utilizado la lengua alemana para la resolución de problemas y la creación de diálogos, escenas y personajes, el análisis actancial de la semiótica para la creación de la estructura de la segunda escena, y la traducción a varios idiomas del poema que constituyó la simiente y el eje de la tercera escena.

Lenguaje escénico, lenguaje verbal y no verbal, lenguaje corporal, lenguaje al fin y al cabo. El Teatro es comunicación, y hemos trabajado en el aspecto lingüístico en varias capas y diferentes aspectos sobre la escena. Los ejemplos de trabajo aquí expuesto enlazan perfectamente el trabajo dramático y escénico con el lingüístico y sirven de ejemplos vivos de cómo no sólo el teatro puede contribuir y enriquecer el aprendizaje de una lengua, sino también de cómo el proceso de aprendizaje y el uso de una lengua puede enriquecer el hecho teatral.

Otro de los aspectos fundamentales para el éxito del proyecto ha sido el compromiso de los alumnos en todo 
momento con el trabajo. Ello se debe a dos factores: la creación en grupo y el trabajo con situaciones reales de su interés. Los alumnos son responsables del proceso de creación, tienen que escribir diálogos, documentarse (lo cual les encanta), crear personajes, estudiar los movimientos y crear pequeñas escenas en grupo. Este trabajo a veces se hace junto con la directora, y en ocasiones se hace en pequeños grupos y luego se presenta a los compañeros. El producto final es resultado de su trabajo como grupo y son sus ideas las que se van a poner en escena. La implicación con este tipo de trabajo es mil veces mayor que con un texto ya escrito que no les pertenece desde el principio.

Existe también una gran diferencia de implicación con referencia a la temática. En ocasiones anteriores, cuando hemos trabajado con textos literarios o teatrales previamente escritos, el trabajo ha sido enriquecedor, pero no ha alcanzado el nivel de implicación y profundidad que alcanzó Grenzen. El tema del conflicto bélico que produce refugiados hace referencia a una realidad muy tangible que les preocupa y sobre la que discuten acaloradamente si les das unos minutos. Tener la oportunidad de visibilizar esa preocupación y dar voz a sus preocupaciones y deseos convierte el hecho teatral en una catarsis colectiva de primer orden.

Por último, me gustaría dar voz a los verdaderos protagonistas de este trabajo para que sean ellos quienes redondeen esta exposición con el relato de su experiencia personal.

\section{Los alumnos, su proyecto, su experiencia}

María (actriz): "Ningún otro personaje de los que he interpretado en Toi Toi Toi me ha supuesto lo que estos en términos de trabajo como actor aficionado y respuesta obtenida del público. En esta obra hemos conseguido tener entre los actores aún más complicidad que la que ya existía, y es un aspecto que, en el escenario, se nota.

Quedarte bloqueado en mitad de la escena sin que te salgan las palabras, aunque te las sepas de memoria y las hayas dicho mil veces, es una situación que no le deseo a nadie por el mal rato que se pasa. Pero poder salir adelante con unas palabras que no están en el guión y que el resto de la escena siga su curso sin más contratiempos, significa que estás metido en tu personaje, que lo conoces y el trabajo realizado se ve."

Cristina (actriz): "Para mí el trabajo de Grenzen es sin duda el mejor que hemos hecho, en gran parte porque ya somos un grupo cohesionado que trabaja muy bien unido, de manera que cuando nos reunimos, aunque dispersemos bastante, siempre surgen ideas, y sabemos construir sobre las ideas de los demás. De esta manera poco a poco y con aportes de todo el grupo conseguimos crear algo de lo que todos estamos orgullosos, porque tiene algo de todos nosotros. En cuanto al aporte que ha tenido sobre mi aprendizaje del alemán, ya hace tiempo que vengo diciendo que si no fuera por el teatro posiblemente me habría rendido, pero el poder utilizarlo además de como un fin, como un medio para crear algo... creo que es mi mayor motivación para seguir aprendiendo."

Gustavo (actor): "Siempre habíamos creado y representado nuestras obras, propias o adaptaciones para amigos, conocidos y compañeros estudiantes de alemán, pero con „Grenzen“, además, nos permitió crecer, marcarnos un objetivo más grande, ante un público ajeno a nosotros pero que a su vez estaba inmerso en nuestra propia corriente de hacer teatro en un idioma en lengua extranjera. Crecimos como personas, al trabajar, crear y representar desde los distintos puntos de vista que un concepto tan humano como son los límites y las fronteras.

Y también dimos un paso adelante al salir de nuestra ciudad $y$ de nuestra zona de confort. Crecimos lingüisticamente, leyendo y aprendiendo vocabulario y expresiones de múltiples artículos en alemán usados como documentación sobre una realidad que nos atañe cada día y que muchas veces obviamos, porque nos resulta más fácil, pero que indirectamente causamos y es que „Woanders wird auch nur mit Wasser gekocht”"”

Erika (actriz): "Para mí Grenzen fue un gran proyecto. Es una obra que juega con sentimientos y sensaciones muy fuertes, debido en gran medida a su temática, tratando temas sobre los que merece la pena reflexionar, lo cual nosotros hicimos, al crear toda la obra partiendo simplemente del concepto "frontera", "límite" (Grenzen). El desarrollo de todo lo que la obra implicaba me hizo crecer un poquito como persona.

También fue una experiencia magnifica poder interpretarla fuera de nuestra ciudad, lo que permitió que antiguas integrantes del grupo pudieran participar. Por otra parte, hacer teatro en una lengua extranjera como es el alemán es una manera formidable de mejorar el idioma, pero además esta vez incluimos otros idiomas, lo que fue una experiencia muy enriquecedora, y que le otorgó a la obra diversidad, consistencia, y facilitó su comprensión por parte del público (haciéndoles así más partícipes y que pudieran disfrutar más de ella).

Fue un proyecto maravilloso a muchos niveles y me siento orgullosa y agradecida de haber formado parte de él." 
Miguel (técnico): “Todo comenzó cuando la directora trajo la propuesta de hacer una obra con temática fijada (fronteras) y una idea atrevida: "quiero asaltar un teatro". Su pasión por la interpretación ha sido siempre el eje de este grupo. Ella les dio alas a los actores, pero fueron ellos los que aprendieron a utilizarlas, creando día a día un complejo universo de la nada. El resultado fue impactante.

Lo que comenzó como un experimento intelectual: un mundo imaginario que reflejara las injusticias del nuestro, les fue implicando y acabaron poniendo tanto sentimiento que las tragedias ficticias se convirtieron en reales, el sufrimiento era real, conmoviendo al propio escenario, dejando sin respiración al público. Y entonces, tras la última representación, un sentimiento agridulce, hermano de la nostalgia (seguramente exista un término especifico en la lengua de Goethe). Un vacio, pues el mundo en que pusieron tanto de ellos mismos no volvería a cobrar vida, sus personajes y sus historias dejarían de existir.

¿Qué me aportó Grenzen? Estoy más interesado en el idioma y conozco más palabras, pero sobre todo, me robó un trocito de corazón. Bergenland vive."

\section{FICHA ARTÍSTICA Y TÉCNICA \\ Grenzen \\ Idea original de "Toi, toi, toi Theater"}

SchauspielerInnen/Actortrices: Aldara García-Miranda, Carlos Alonso Brasas, Cristina del Blanco Burón, Erika Mota Casas, Gustavo Martínez Pérez, María Fernández Alonso, Sonia Fernández Rodríguez y María V. Barrio Corral.

Techniker/Técnico: Miguel Ángel Mayoral.

Bühnendekoration, Kostüme, Requisiten/Escenografía, Vestuario y Atrezzo: Toi, toi, toi Theater.

Regie/Dirección: Leticia García Brea.

Musik/Música: Ruthless - Amon Tobin, Alexander Balanescu - To the hills, Balanescu Quartet - Life and Death, 17 Hippies - Ungefähr.

3. Szene Gedicht/Poema 3a Escena: “Home” de Warsan Shire (original en inglés, traducciones libres).

Danke an/Gracias a: Centro de Idiomas de la Universidad de León, por cedernos el espacio para ensayar y crecer juntos. Judit, Yasmín y Quino, por vuestros apreciadísimos consejos y ayuda en el proceso creativo. Berta, Rocía, Sandra y Carmen (antiguas compañeras de reparto), por venir a vernos y darlo todo sobre el escenario con nosotros en Madrid.

- Estreno: I Festival de Teatro En Lengua Extranjera el 10 de abril de 2016 en el Teatro "El Umbral de Primavera" de Madrid.

- (Extracto) Jugendtheaterfestival en el Goethe Institut de Madrid el 16 de abril de 2016.

- (Grabación) Centro de Idiomas de la Universidad de León el 22 de abril de 2016. https://www.youtube.com/watch?v=WAw0-Or1MTU\&feature=youtu.be

TOI, TOI,TOI THEATER

toitoitoitheater.blogspot.com

Canal de Youtube: ToitoitoiTheater Deutsch

Bibliografía

Pérez Rufí, Jose Patricio (2008): El análisis actancial del personaje: una visión crítica en Espéculo. Revista de estudios literarios. Universidad Complutense de Madrid (http://www.ucm.es/info/especulo/numero38/modactan.html) 